\title{
Analysis of the patients with lichenoid drug reactions: a retrospective study
}

\author{
Ayse $_{\text {Akbas }}{ }^{*}$, Fadime Kilinc $^{1}$
}

\begin{abstract}
Objective: Lichenoid drug reactions (LDR) are a rarely known type of drug reaction that resembles lichen planus. The exact etiology of LDR is not known but it is thought to be caused by the triggering of all kinds of chemical substances. In this study; we aimed to investigate the clinical and demographic characteristics of the patients who were diagnosed with LDR.

Material and Method: The files of 56 LDR patients who were followed in our outpatient clinic among 2011 2016 have been reviewed retrospectively. The demographic characteristics, the drugs considered to cause reaction, the presence of multiple drug usage, the duration between drug intake and appearance of the initial skin eruption, clinical findings, lesion locations, laboratory findings and associated diseases have been recorded.
\end{abstract}

Results: Out of the 56 LDR patients, who were clinically and histopathologically diagnosed and followed, 36 were female and 20 were male. The average age was 52.8 (19-86 years of age). The duration of the symptoms was between 1-3 months in 58.9\% of the patients, between 3-12 months in \% 17.8, between 1 to 30 days in \% $14.2(n=8)$ and more than 1 year in $8.9 \%$ of the patients. $48.2 \%(n=27)$ of the lesions were on the extremities, $37.5 \%$ were generalized, $7.1 \%$ were invers type. The most frequently accused drug groups were nonsteroidal anti-inflammatory drugs (NSAID) and antihypertensive.

Conclusions: It has been found that the use of NSAID, and cardiovascular drugs on their own and / or in combination with other medications often led to lichenoid drug reactions.

Keywords: Lichenoid, drug, reaction, nonsteroidal, anti-inflammatory, antihypertensive

\section{Introduction}

Drugs are chemical substances that are used in the diagnosis, treatment and prevention of diseases. On the other hand, drugs frequently have unwanted side effects(1). With the advancement of science and technology, the discovery of new medication and the increase of their usage, undesirable drug reactions have been a major problem and a current issue (2-4). It has been suggested that approximately $2 \%$ of the patients develop a drug-induced skin reaction (1).

Drug allergies have a different range of symptoms including a slight color change up to alife-threatening picture. While exanthematous, morbiliform, maculopapular, urticarial, and generalized pruritus are the most common skin reactions. The lichenoid drug reactions (LDR) are rarely seen (1). As indicated in various studies the ratio varies between 1.9 to $6 \%$ (510).

LDR can show up with various medications around the world (2-4).
The information about epidemiology is very limited and the frequency varies according to the population studied $(5,11)$.

It may be due to the fact that the same group of medicines are not preferred in all populations. It has been found that LDR generally appear at the end of very long periods of drug intake and they are seen less frequently when compared with other drug reactions $(3,12)$.

These have been reported in domestic and foreign literature mostly case reports of patients who were hospitalized $(4,13-28)$. We did not come across in the literature with any study that investigates only LDR.

For that reason, we aimed to research the clinical and demographical characteristics/ of the patients who are suffering with LDR, uncommon disease disturbing patients for a long period of time.

Received 19-03-2018 Accepted 28-03-2018 Available Online 31-03-2018 


\section{Material and Method}

Our study project was approved by local ethics committee (IRB (Institutions review board) number: $11 / 02 / 2015$ date and number 26379996/65). In this study we retrospectively reviewed the medical records of 56 adult patients who were admitted to our outpatient clinic between January 2011 and December 2016 with a diagnosis of LDR. All patients were diagnosed with biopsy and histopathological examination. Data obtained from the records included the demographic characteristics such as age, sex, clinical findings, lesion location, coexisting diseases, the drugs used by the patient continuously and the duration of the skin eruption.

In all patients detailed history was taken in regard to drug intake. In addition, care was taken to select cases whose symptoms were improved or declined when suspected drug was stopped. The laboratory findings of the patients were also recorded. The drug groups were mostly nonsteroidal anti-inflammatory drugs (NSAID), antihypertensive (beta-blockers, angiotensin converting enzyme (ACE) inhibitors), antiarrhythmic, antidiabetic and neuropsychiatric drugs, vitamins, antacids, antiepileptics, antibiotics and combined drugs. The duration between the intake of the suspicious drug (s) and the development of the skin eruption was divided into groups of 1 to 30 days, 1-3 months, 3 months - 1 year and more than 1 year.

All these findings were evaluated and compared with general literature.

\section{Statistical Analysis}

A detailed statistical analysis was made based on the acquired retrospective data. Statistical analysis was performed using SPSS software, Version 20 (SPSS Inc., Chicago IL, USA). Frequencies were calculated for variables related to demographic and clinical patient characteristics. Qualitative variables were expressed as percentage. Quantitative variables were expressed as mean.

\section{Results}

There were 56 LDR patients who were diagnosed and followed clinically and histopathologically in our outpatient clinic. 36 of these patients were female and 20 of them were male. The female / male ratio was 1.8. The average age was confirmed as 52.8 (between 19-86 years). The average age was 56 for women and 46.6 for men. The most common age range was $50-70$ $(58.9 \%, \mathrm{n}=27)$. The percentage of the patients according to age and gender has been shown in Table1.

The time elapsed from the first intake of the medication / drug until the beginning of the skin eruption ranged from 10 days to 15 years. The time elapsed from the drug ingestion to the eruption of the lesion was at most at the rate $58.9(\mathrm{n}=33)$ between $1-3$ months. $17.8 \%$ was between $3-12$ months $(n=10), \%$.
14.2 was between $1-30$ days $(n=8), 8.9 \%(n=5)$ complained more than 1 year. When evaluated in terms of symptoms only 9 patients $(16 \%)$ had itching. When evaluated in terms of localization, the extremities were the most frequent localization with a ratio $48.2 \%$ (Figure 1,2).LDR was generalized in $37.5 \%(n=21)$ of the patients, invers in $7.1 \%(n=4)$ and localized in $5.3 \%(\mathrm{n}=3)$ of the patients in which lesions were only on the face and hands. In one patient it had a scapular zosteriform shape (\% 1.7) (Figure 3).

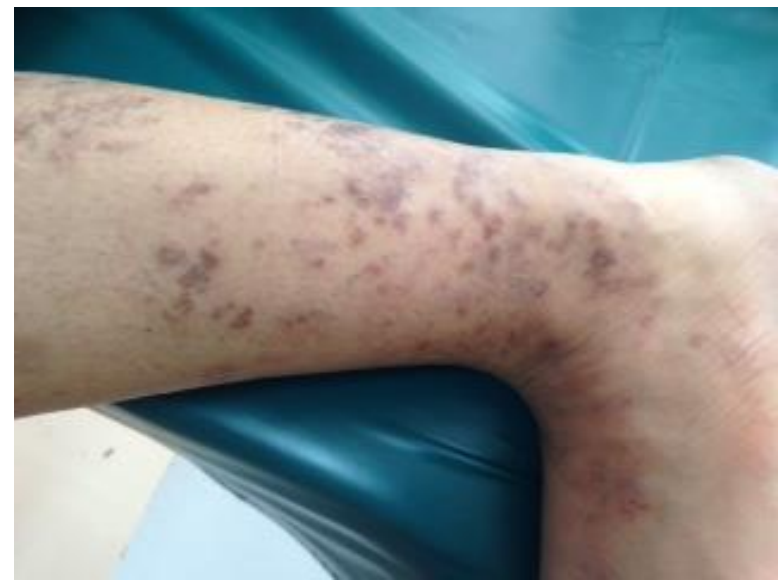

Figure 1: Hyperpigmented lichenoid lesions located on leg.

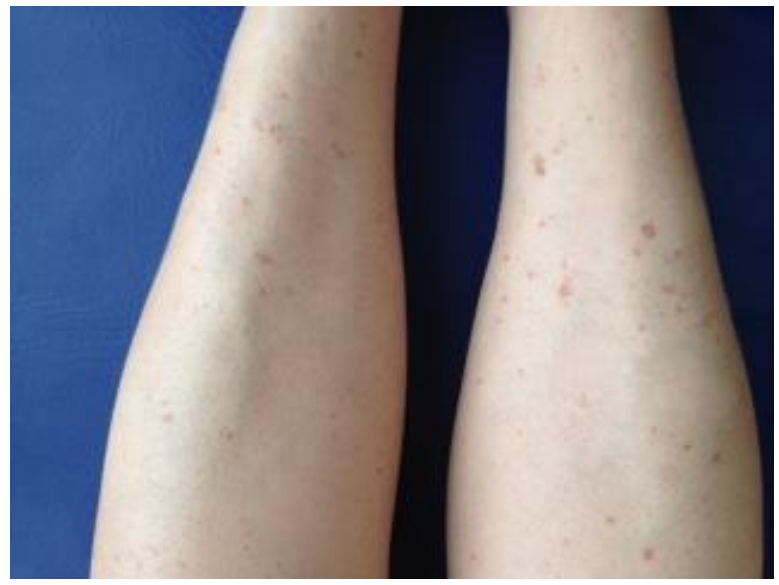

Figure 2: Bilateral lichenoid lesions.

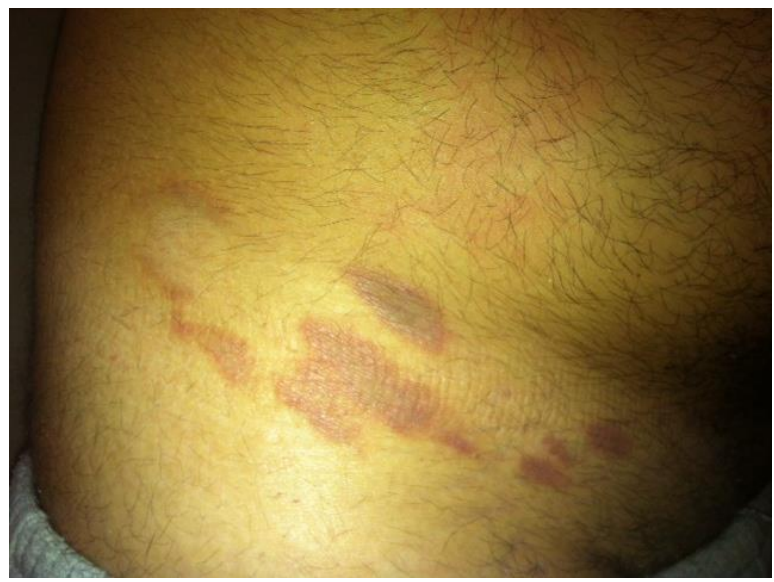

Figure 3: Zosteriform lichenoid lesions on the trunk. 
Table 1: The percentage of the patients according to age and gender

\begin{tabular}{cccccc} 
Age & Med age & Male & Female & Total & Rate(\%) \\
$\mathbf{1 9 - 2 9}$ & 22.8 & 6 & 1 & 7 & 12.5 \\
$\mathbf{3 0 - 3 9}$ & 34.3 & 2 & 4 & 6 & 10.7 \\
$\mathbf{4 0 - 4 9}$ & 45.6 & 3 & 6 & 9 & 16.2 \\
$\mathbf{5 0 - 5 9}$ & 55.4 & 2 & 8 & 10 & 17.8 \\
$\mathbf{6 0 - 6 9}$ & 63.7 & 4 & 10 & 14 & 25 \\
$\mathbf{7 0 - 7 9}$ & 72.2 & 2 & 5 & 7 & 12.5 \\
$\mathbf{8 0 - 8 9}$ & 84 & 1 & 2 & 3 & 5.3 \\
Total & 52.8 & 20 & 36 & 56 & 100 \\
\hline
\end{tabular}

Table 2: The time elapsed from drug ingestion until the skin eruption

\begin{tabular}{lcc} 
Time & Patient no (n) & Patient rate $(\%)$ \\
\hline 1-30days & 8 & 14.2 \\
1-3months & 33 & 58.9 \\
3-12months & 10 & 17.8 \\
$>$ 1 year & 5 & 8.9 \\
\hline
\end{tabular}

Table 3: Lesion localization and rates

\begin{tabular}{lcc}
\multicolumn{1}{c}{ Lesion location } & Patient no (n) & Patient rate (\%) \\
\hline Extremities & 27 & 48.2 \\
Generalized & 21 & 37.5 \\
Invers & 4 & 7.1 \\
Face and hands & 3 & 8.9 \\
Zosteriform & 1 & 1.7 \\
Genital and oral mucosa & - & - \\
Hair and nail & - & - \\
\hline
\end{tabular}

Table 4: Accompanying diseases and rates

\begin{tabular}{lcc} 
Concomitantdiseases & Patient no (n) & Patient rate (\%) \\
Hypertension and coronary artery diseases & 21 & 37.2 \\
Anemia & 11 & 19.6 \\
Diabetes mellitus & 8 & 14.2 \\
Neuropsychiatric diseases & 7 & 12.5 \\
Gastrointestinal complaints & 6 & 10.7 \\
Thyroid diseases & 5 & 8.9 \\
Elevation of liver enzymes & 4 & 7.1 \\
Fungal infections/Polyarthritis,/Myalgia & 3 & 5.3 \\
Astma/Menstruel irrgularity & 2 & 3,5 \\
Lichen planus pigmentosus(LPP)/Psoriasis & 2 & 3.5 \\
Osteoporosis/Epilepy/Renal impairment/Pelvic inf & & \\
/Allergic rhinitis/Venous insufficiency/Migraine/Cerebro & 1 & 1.7 \\
vascular disease/Pneumonia/ Irritable bowel syndrome & & 46.6 \\
Presence of multiple illnesses & 25 & \\
\hline
\end{tabular}


Table 5: Drugs causing lichenoid reaction and rates

\begin{tabular}{|c|c|c|}
\hline Drugs & $\begin{array}{l}\text { Patient } \\
\text { (n) }\end{array}$ & $\begin{array}{c}\text { Patient } \\
\text { Rate }(\%)\end{array}$ \\
\hline $\begin{array}{l}\text { NSAID; } \\
\text { DiclofenacPotassium (1), AcidSalicylicAcid (ASA)(3),NaproxenSodium (1), } \\
\text { Flupirofen(1),Dexketoprofen (1),Meloxicam (1), } \\
\text { DeksketoprofenTrometamol(1), } \\
\text { Unknown (18) }\end{array}$ & 27 & 48.2 \\
\hline $\begin{array}{l}\text { Antihypertensive + Antiaritmicdrugs; } \\
\text { Amliyodipin(6 ), IsosorbideDinitrat (1),Trimetazon(1),Propranolol(1), } \\
\text { Metoprolol(2), BenipinHydroclorur(1), CandisartanHydroclorur(1), } \\
\text { Dihydropiridin(1), Atenolol(1),ValsartanHydrochlorothiazide(1), } \\
\text { Ramipril(2), LosartanPotassium(1), Telmisartan(1) }\end{array}$ & 21 & 37.5 \\
\hline $\begin{array}{l}\text { Antidepressans; } \\
\text { Sertraline (2), 5-Hydroxytryptamine (1), Sitalopram (1), Risperidone (1), } \\
\text { Essentialopram (1), Amitriptyline (1) }\end{array}$ & 7 & 12.5 \\
\hline Antidiabetics ;Metformin (4), Glycidase (1), Insulin (1) & 6 & 10.7 \\
\hline $\begin{array}{l}\text { Gastrointestinaldrugs; } \\
\text { Lansoprol (2), Pantoprazole Hydrotalcite (1), Esomeprazole (2), } \\
\text { Famotidine(1), Sodiumalginate + Potassiumbicarbonate (2), } \\
\text { Dihydroxyaliminium(1) }\end{array}$ & 6 & 10.7 \\
\hline Diuretics;Furasamide (1), Indapamide (2), Perindopril (1) & 4 & 7.1 \\
\hline AntithromboticDrugs ;ClopidogrelhydrogenSulfate(4) & 4 & 7.1 \\
\hline Antifungal;Terbinafine (1),Griseofulvin (1),Fluconazole (1) & 3 & 5.3 \\
\hline Antiastmadrugs ;Fluticasonepropionate (3) & 3 & 5.3 \\
\hline Antityroiddrugs; Levothyroxine (3) & 3 & 5.3 \\
\hline Acetaminophen/paracetamol; (3) & 3 & 5.3 \\
\hline Antibiotics; Quinolone (1), Ornidazole (1), Metranidazole + Imidazole (1) & 3 & 5.3 \\
\hline $\begin{array}{l}\text { Mylelorelaksan; Thiocolchicine (2), Tizanidine) (1),Cyanocobalamin (2), } \\
\text { Piracetam(1) }\end{array}$ & 3 & 5.3 \\
\hline Vit B12;Cyanocobalamin (2) & 2 & 3.5 \\
\hline Iron preperats;IronOxide (2) & 2 & 3.5 \\
\hline Hormone ; OralContraceptive (2) & 2 & 3.5 \\
\hline Anti Lipidemics;Simvastatin (2) & 2 & 3.5 \\
\hline Serebrovaskulerregulator; Piracetam(1), & 1 & 1.7 \\
\hline Antiosteolitic ;AlendronicAcid(1) & 1 & 1.7 \\
\hline $\begin{array}{l}\text { Other drugs; } \\
\text { Acetylcysteine (1), Betamethasone dipropionate (1), } 1.25 \text { Cholecalciferol (1), } \\
\text { Leflumid, Entekavir = Baraclude (1), MonteclastSodium (1) }\end{array}$ & 5 & 8.9 \\
\hline
\end{tabular}

There was no patient with hair, nail, oral and genital mucosa involvement. Lesion localization and rates are shown in Table 3.

The percentage of concomitant diseases are shown Table 4 . The others received medication because of pain, fever, etc. No hepatitis $\mathrm{B}$ and $\mathrm{C}$ were detected in any of the cases.

It has been found that the most accused drug groups were NSAID and drugs for the cardiovascular system (anti-hypertensive, cardiac drugs, diuretics, anticoagulants). The $48.2 \%(n=27)$ of the patients were using NSAID.

This was followed by the patients who were using antihypertensive and cardiac drugs with $37.5 \%$ $(n=21)$.
This was then followed by antidepressants, antidiabetics, gastrointestinal drugs, antibiotics and antifungals respectively.18 of 27 cases used NSAID the name of which they did not know for pain or fever reasons.

The time periods from drug uptake until the appearance of skin eruption has shown in Table 2.

When the drugs that are considered to be responsible for LDR in patients were examined; In 21 patients (37.5\%) antihypertensives, ACE inhibitors / cardiac drugs, in 27 patients (48.2\%) NSAID, in 7 patients $(12.5 \%)$ neuropsychiatric drugs, in 6 patients $(10.7 \%)$ $\mathrm{H} 1$ receptor antagonists and antidiabetics were found. In 4 cases $(5.3 \%)$, diuretics, anticoagulants; in 3 cases antibiotics, vitamins, muscle relaxants, antithyroid drugs, antifungal agents, paracetamol in 2 cases iron 
deficiency drugs and antiacids, in one patient $(3.5 \%)$, antiosteolytic, cerebrovascular regulator (1.7\%), simvastatin (antihyperlipidemic) and antiepileptic drugs were used.

In $31(55.4 \%)$ of the cases followed at our outpatient with LDR diagnosis, the use of single agent was responsible for the drug reaction, whereas in 25 patients $(44.6 \%)$, the use of combined drugs was responsible for the eruption.

The most frequently observed combination was antihypertensive, anticardiac drugs and diuretics with a frequency of $14 \%$.

Drugs causing lichenoid reaction and rates is shown in Table 5.

\section{Discussion}

Nowadays, the discovery of new medicines, the increasing usage of medicines and the prolonged usage of the drugs and together with the increased life span have increased the effect of drugs on humans(1). Up to now, numerous medications have been reported to cause LDRs and a new one is added at every passing day $(29,3)$. The first data belonging to LDR were the cases that include arsenic which was used for the syphilis treatment in year 1929 and the gold and antimalarial usage for rheumatoid arthritis that was reported in 1940 (10,29-31). Afterwards it has been reported that too many drugs caused this eruption (25,28-33). But LDR mostly caused by and NSAID and antihypertensive drugs $(25,28-33)$.

The rate of incidence of LDR in cutaneous drug reactions is very low (10). While Puavilai detected $1.2 \%$ case LDR in 80 disease cases series in 1998, Qayoom detected 4\% in year 2015 (6,34). As the drug diversity increases, the possibility of LDR appears to increase. In our country this ratio varies between $1.9 \%$ and $6 \%(4,7-9,26,33,34)$.

In general, the main drugs that cause to a drug reaction are NSAID and cardiac drug groups. It has been found that the chances they cause LDR are also high $(31,33)$. The NSAID that can be obtained without prescription and thus frequently used in complaints such as pain, fever, etc. are easily accessible at all times are causing the most frequent LDR (35). In our country, Ozkan et al. carried out a research with 92 patients with lichen planus and found out that the most frequent triggering drug for lichen planus is NSAID and they have the potential to cause lichen planus like skin eruption (36). In the foreign literature, different studies have also shown these drugs are causing LDR $(6,19,37,38)$. We have obtained similar results in our study. Even though some studies have reported that the NSAID would cause oral lichenoid reactions, in our study even though there were many patients with skin lesions. Interestingly there were no cases of oral lesions (37).
Another group of drugs that is reported to be the most common cause of LDR is ACE inhibitors, betablockers, cardiovascular drugs including thiazide group diuretics $(10,14,20-24,27,39-42)$. Upadhayai et al. found that atenolol and amlodipine were the main drugs causing LDR in their studies where they used antihypertensive agents (39). In our study, similar to the literature, LDR developed secondary due to antihypertensive drugs. 21 of our patients were taking antihypertensive drugs. We observed that amlodipine was the cause in 6 of these cases. Fessa et al. claimed that LDR was the result of the suppression of the adrenergic system in the skin or the result of the drug cross adrenergic (40).

The neuropsychiatric drugs may trigger LDR $(43,44)$. Akpinar et al. reported in their study with 106 cases that the 3 patients with LDR were using neurologic drugs (8). In our study, there were 6 patients who were receiving antidepressant medication.

Sulfonylurea and anti-hypoglycemic drugs may cause LDR, especially in elderly patients (45). We had 6 patients using antihyperglycemic agents.

The main problem in diagnosis and treatment of LDR is the ability to describe the offending drug responsible for patients who are taking more than one drug. Because while drugs can make LDR alone, sometimes they can potentialize the lichenoid effects of other drugs (10).

In our study when we observe generally, while the use of single drug was observed in $55.4 \%$ cases, the rate of the combined agents was determined as $44.6 \%$. Among these treatments, the use of the NSAID or together with acid salicylic acid (ASA) or with the cardiac drugs (frequently beta blockers and ACE inhibitors) was taking a place on the forefront.

We have found out as a result of our studies that the cutaneous drug reactions are more frequent in females than males and in adults than in children $(33,46)$. The fact that females have more autoimmune diseases, tendency to hypersensitivity and the use of more medications may facilitate this $(10,46)$. In our study we also had a $61 \%$ female superiority and were have also found that LDR are more frequently seen over 30 years of age.

The time that elapsed after the development of LDR, until the patient's application can take months (33).This duration of time can vary from a few months to years. This is especially specific when taking multiple medicines. This time may vary according to the dosage of the drug, the response of the site, the presence of previous exposure and the intake of different drugs at the same time. Apart from that, there may also be a delay in the diagnosis due to different skin findings such as psoriasiform or eczematous lesions (12). The time to emergence of the lesions was reported to be 2 months to 3 years for penicilamine, 1 years for beta blockers, 3 to 6 months for ACE 
inhibitors, and 4-6 weeks for quinacrine $(3,31,33)$. Upadhayai et al. have determined the time of formation for LDR as 19.6 months on an average (39). In our study, the duration of the lesion appearance was between 1 month and 3 months in $58.9 \%$ ( 33 cases) of the patients. Only at 5 cases it took more than a year. In one of these cases, the medication taken by the patient for 15 years had reacted. As in our cases, the lesion receded within months by stopping the responsible agent. No latent period could be determined because the NSAID were being taken every now and again.

Lichenoid rashes were observed in the photosensitive regions of the thiazide group diuretics, diltiazem, quinine, quinidine tetracycline, etambutol, and chlorpromazine group drugs $(3,22,23,30)$. Puavilai et al. determined photo lichenoid eruption in a patient using thiazide group drug (34). In our study, we observed a photosensitized lichenoid drug reaction in the face and hands of three patients using thiazide group diuretic and antihypertensive combination of drugs.

LDR is known to be a rare disease (31). In our study that we have conducted, we have seen that this disease is actually not a very rare disease. The reasons for under diagnosis of LDR are appearing after a very long period after the intake of the drug, being eczematous apart from the lichenoid appearance, having papular, plaques or desquamation shape. Thus LDR is generally overlooked and the main diagnosis is delayed (33). Therefore, the definitive diagnosis may also be difficult. Especially it is difficult to distinguish it from classical lichen planus by clinically and histopathologically (31). Also preliminary diagnoses and the histopathologic diagnosis can be incompatible (47).

Even though there are similarities to lichen planus histopathologically, the presence of eosinophils, findings such as focal parakeratosis, lymphoid cell exocytosis into the upper epidermal layers, colloid bodies in the dermoepidermal compartment, cell infiltration around the deep veins are more common in LDR $(3,33,47)$ Clinical manifestation, histopathological findings, drug intake history and the positivity at the drug patch and / or provocation test can guide to the definitive diagnosis. The diagnosis of all the cases in our study was supported by histopathologically. Apart from this, the lesions were improved by stopping the drug which were blamed and the lesions were repeated when the drug was started again.

In LDR, lesions may be limited to a small area in the skin but also it can be generalized throughout the body. Unlike the typical flexural involvement of the lichen planus, it is located more on the extremities and trunk (31). In most of the cases, the lesions were located symmetrically in the upper and lower extremities in 27 cases. In 21 cases, more than one involvement was mentioned. There were inverse localizations in only 5 of our cases. There was a hand and face localization in 3 patients. There was only one zosteriform site in a patient. None of our patients had any hair, oral, genital or nail involvement as in the literature.

It has not been clearly determined by which means the medicines caused LDR. Delayed type 4 hypersensitivity reactions are thought to cause the drug to merge with the epidermal proteins and to transform the epidermis to an antigenic state by acting like a hapten $(2,48,49)$. The dose of the drug, host reaction, predrug exposure and concomitant drug intake all affect the LDR pathogenesis (2-4). The presence of autoimmune diseases may also facilitate the emergence of LDR. In our study, 2 patients had LPP and 1 patient had psoriasis history. In addition, our patients had associated autoimmune diseases such as arthritis, diabetes, thyroid diseases, vitamin B12 deficiency anemia, etc. Also, medicines used against these diseases could facilitate the emergence of LDR (10).

LDR can be seen in all age groups around the world. While people in middle-age and older age are the high-risk groups for the development of drug reactions, this is very rare in children (11). In patients over 65 years of age, renal and hepatic functions lead to more physiological decline, multiple disease agents and multiple drug use, drug-disease interactions, drugdrug interactions and forgetfulness $(46,50)$. Dilek et al found that in their study which they conducted with people over 55 years of age, that with the increase of age, the drug reactions increase (46). The average age at our study was 52.8 years. However, especially in patients over sixty years of age (which constituted $41 \%$ of these cases), skin lesions were both more common and diffuse. In 4 patients, liver enzyme elevation was determined whereas in 1 patient renal insufficiency was detected.

The treatment of LDR is the detection of the drug causing the disease and its interruption. In our cases, the lesions of the patients disappeared after the medication was interrupted. Furthermore, symptomatic treatment such as topical and systemic corticosteroids may also be given (3). We have also provided symptomatic treatment.

\section{Conclusion}

The patients with LDR may come across us with various clinical features. It is important that the clinical characteristics of the patients are well known because of the fact that the LDR are identified and that the symptoms and findings are forming a basis.

It has been determined that the drugs containing NSAID which are commonly used due to the fact that they can be purchased without prescription are causing LDR. Care should be taken regarding the possible cutaneous side effects of drugs in patients, 
especially in the presence of multiple and long-term drug use and advanced age.

In the elderly population where secondary diseases increase, one should avoid the use of combined drugs.

Dermatological examination as well as the monitoring of the drugs at regular intervals will be effective in reducing the side effects of the drugs. Cessation of the stimulant drugs that are determined by the detailed drug anamnesis interrogation is important in terms of increasing the success of the treatment and preventing recurrences. And this will increase the quality of life of the patient.

The feedback on drug side effects is important all over the world. For this purpose, in year 1985, TUFAM (Pharmacovigilance Center of Turkey) was established in our country (4). However, this center is not very effective in reporting the LDR due to its longterm appearance and sometimes due to the misdiagnosis.

\section{Acknowledgments, Funding: None}

Conflict of Interest: The authors declare no potential conflicts of interest with respect to the research, authorship, and/or publication of this article.

Author's Contributions: AA, FK: Research concept and design; Retrospective data collecting, analysis and interpretation of data. All authors approved the final version of the manuscript,

Ethical issues: All Authors declare that Originality of research/article etc... and ethical approval of research, and responsibilities of research against local ethics commission are under the Authors responsibilities. The study was conducted due to defined rules by the Local Ethics Commission guidelines and audits.

\section{References}

1. Dinçer D. Drug Reactions in Dermatology. Turk J Dermatol 2013;7: 179-84

2. Erkek E. Kutanozilac reaksiyonları. In: Tuzun Y, Gurer MA Serdaroğlu S, Oğuz O, Aksungur VL (editorler). Dermatoloji 3. Bask1, İstanbul: Nobel Tip Kitabevleri, 2008:269-316

3. Shiohara T, Kano Y. Lichen planus and lichenoid dermatosus In Dermatology (Bolognia JL, Jorizzo JL, Rapini RP et al, eds) 2nd edn. Newyork: Mosby, USA 2008;159-80.

4. Ozturk HZY, Sarıcaoğlu H, Yazıcı S,et al. Analysis of the inpatients with drug reactions: a retrospective study. Uludağ Üniversitesi Tıp Fakültesi Dergisi 2010;36:75-80.

5. Fiszenson-Albala F, Auzerie V, Mahe E, Farinotti R, etal. A 6 month prospective survey of cutaneous drug reactions in a hospital setting. Br J Dermatol 2003 Nov;149(5):1018-22.

6. Qayoom S, Bisati S, Manzoor S, et al. Adverse cutaneous drug reactions-a clinico-demographic study in a tertiary care teaching hospital of the Kashmir Valley India. Arch Iran Med 2015 Apr;18(4):228-33.
7. Turk BG, Gunaydin A, Ertam I, et al.. Adverse cutaneous drug reactions among hospitalized patients: five year surveillance. Cutan Ocul Toxicol 2013;32(1):41-5

8. Akpinar F, Dervis E. Drug eruptions: An 8-year study including 106 inpatients at a dermatologyclinic in Turkey. Indian J Dermatol 2012;57(3):194-8.

9. Dertlioğlu N, Çiçek D, Çoban FG. .Drug reactions seen among patients admitted to the dermatology department. Turkderm 2012;46: 130-3

10. Ellgehausen P, Elsner P, Burg G. Drug-induced lichen planus. ClinDermatol 1998;16(3):325-32

11. Mittal N, Gupta M, Singla M. Cutaneous adverse drug reactions notifed by pharmacovigilange in a tertiary care hospital in North India. Cutan Ocul Toxicol 2014; 33(4):289293.

12. Ahmed AM, Pritchard S, Reichenberg J. A review of cutaneous drug eruptions. Clin Geriatr Med 2013;29:527-45.

13. Gupta M, Gupta H, Gupta A. Tenofovir induced lichenoid drug eruption. Avicenna J Med 2015;5(3):95-7.

14. Sebök B, Tóth M, Anga, et al. Lichenoid drug eruption with HMG-Co a reductase inhibitors (fluvastatinandlovastatin). Acta Derm Venereol 2004;84(3):229-30.

15. İyidal AY, Çokbankir Ö, Kılıç FA. Etanercept treatment induced lichenoid eruption: case report . Turkiye Klin J Dermatol 2016;26(1):59-62.

16. Polat $\mathrm{M}$, Üstün $\mathrm{H}$. Oral and cutaneous lichenoid reaction secondary to standard döşe imatinib: a case report and literatur review. Gazi Medika Journal 2014;25: 157-60.

17. Inoue A, Sawada $\mathrm{Y}$, Ohmori S, et al. Lichenoid drug eruption caused by lima prostal fadex. Acta Derm Venereol 2016:2;96(7):997-8

18. Ghosh SK. Generalized lichenoid drug eruption associated with imatinib mesylate therapy. Indian J Dermatol 2013;58:388-92.

19. Powell ML, Ehrlich A, Belsito DV. Lichenoid drug eruptionto salsalate. J Am Acad Dermatol 2001;45(4):616-9.

20. Roten SV, Mainetti C, Donath R, et al. Enalapril-induced lichenplanus-like eruption. J Am Acad Dermatol 1995;32(2 Pt 1):293-5.

21. Ruiz-Villaverde R, Galan-Gutierrez M. Lichenoid drug eruption due to eprosartan/hydrochlorothiacide. Dermatol Reports 2011;Sep 28;3(2):e31.

22. Aouam K, Ali HB, Youssef M, et al. Lichenoid eruption associated with hydrochloro thiazide and possible cross reactivity to furosemide. Therapie 2009;Sep-Oct;64(5):344-7.

23. Sin B, Miller M, ChewE. Hydrochloro thiazide induced lichenplanus in the emergency department. J Pharmv Pract 2017;Apr;30(2):266-69.

24. Hawk JL. Lichenoid drug eruption induced by propanolol. Clinv Exp Dermatol 1980;5(1):93-6.

25. An I, Demir V, Akdeniz S. Lichenoid drug eruption induced by colchicine: case report. Cutan Oculv Toxicol 2017;36(2):199-200.

26. Brauer J, Votava HJ, Meehan S, et al. Lichenoid drug eruption. Dermatol Online J 2009;Aug 15;15(8):13. 
27. Ruiz-Villaverde R, Galan-Gutierrez M. Lichenoid drug eruption due to eprosartan/hydrochlorothiacide. Dermatolv Reports 2011 Sep 28;3(2):e31.

28. Zheng $\mathrm{Y}$, Zhang $\mathrm{J}$, Chen $\mathrm{H}$, et al. Terbinafine-induced lichenoid drug eruption. Cutan Ocul Toxicol. 2017 Mar;36(1):101-103.

29. Lee A, Thomson J Drug-induced skin reactions adverse drug reactions. 2nd edition ISBN 853696012 Pharmaceutical Press 2006;124-156.

30. Halevy S, Sha i A. Lichenoid drugeruptions. J AmAcadDermatol 1993;29:249-55.

31. Lukacs J, Scliemann S, Elsner P. Lichen planus and lichenoid reactions as a systemic diseases. Clinics in Dermatology 2015; 33: 512-19.

32. Gorouhi F, Davari P, Fazel N. Cutaneous and mucosal lichenplanus: a comprehensive review of clinical subtypes, risk factors, diagnosis, and prognosis. Scientific World Journal 2014 Jan 30;2014:742826. doi:10.1155/2014/742826.

33. Sehgal VN, Srivastava G, Sharma S, et al.,Verma P. Lichenoid tissue reaction/interface dermatitis: recognition, classification, etiology, and clinico pathological over tones. Indian J DermatolVenereol Leprol 2011 Jul-Aug;77(4):418-29.

34. Puavilai S, Choonhakarn C. Drug eruptions in Bangkok: a 1year study at Ramathibodi Hospital. Int J Dermatol1998 Oct;37(10):747-51.

35. Onat SȘ. Dermatological adverse effects of nonsteroidal antiinflamatory drugs. Journal of physical medicine and rehabilitation science J PMR Sci 2011;14: 105-13.

36. Özkan Ş, İlknur $\mathrm{T}$, Fetil $\mathrm{E}$ et al. Liken planusta ilaçla uyarılma. Dermatoz 2005;4(4):196- 201.

37. Potts AJ, Hamburger J, Scully CT. The medication of patients with oral lichenplanus and the association of nonsteroidal antiinflammatory drugs with erosive lesions. Oral Surg Oral Med Oral Pathol 1987 Nov;64(5):541-3.

38. Adisen E, Karaca F, Gurer AM. Drug reactions in dermatology. Turk J Dermatol 2008;2:1-5.
39. Upadhayai JB, Nangia AK, Mukhija RD et al. Cutaneous reactions due to anti hypertensive drugs. Indian Journal of Dermatology2006 ;51,3:189-91.

40. Fessa C, Lim P, Kossard S, et al. Lichen planus-like drug eruptions due to $\beta$-blockers: a case report and literatüre review. Am J ClinDermatol 2012 Dec 1;13(6):417-21. doi: 10.2165/11634590-000000000-00000.

41. Roger D, Rolle F, Labrousse A et al. Simvastatin-induced lichenoid drug erupsion. Clin Exp Dermatol 1994:19:88-9.

42. Başar I, Aydemir EH. Cutaneous adverse effects of cardiovasculary drugs. Cerrahpaşa J Med 1999; 30 (4): 28697.

43. Aydın Y, Karakus G, Günaștı S. Psikotrop ilaçların dermatolojik yan etkileri. Klinik Psiko Farmakoloji Bülteni $2008 ; 18,3: 235-2$

44. Fernández-Torres R, Almagro M, del Pozo J, Robles O, et al. Lichenoid drug eruption induced by olanzapine. Actas Dermo sifiliograficas 2008 Apr;99(3):221-4

45. Zaïem A, Sahnoun R, Badri $T$, et al. Lichen associated with metformin. Therapie. 2014 May-Jun;69(3):253-4. doi: 10.2515/Therapie/2014025. Epub 2014 Jun 16.

46. Dilek N, Saral Y, Yüksel D, et al. Cutaneous drug reactions and causative drugs in patients aged 55 years and over. Turkiye Klin J Med Sci 2013;33(5):1295-301.

47. Van den Haute V, Antoine JL, Lachapelle JM. Histopathological discriminant criteria between lichenoid drug eruption and idiopathic lichen planus: Retrospective study on selected samples. Dermatologica 1989;179(1):10-3. (PMID:2527767)

48. Daoud MS, Pittelkow MR. Lichen planus. In: Fitzpatric's Dermatology in General Medicine ( Freedberg IM, Eisen AZ ,Wolf K et al. eds)7th edn New York, McGrawHill , 2012 ;561-77.

49. Boyvat A. İlaç erupsiyonlarında patogenez ve klinik özellikler. Türkiye Klin J Dermatol 2008;1:47-57.

50. Carneiro SC, Azevedo-e-Silva MC, Ramos-e-Silva M. Drugeruptions in thenelderly. Clin Dermatol 2011;29(1):4

Copyright (C) 2018 The Author(s); This is an open-access article distributed under the terms of the Creative Commons Attribution License (http://creativecommons.org/licenses/by/4.0), which permits unrestricted use, distribution, and reproduction in any medium, provided the original work is properly cited. All Rights reserved by international journal of Medical Science and Discovery. 